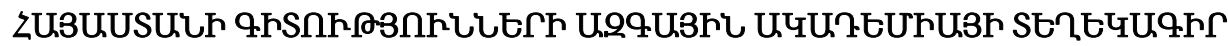 ИЗВЕСТИЯ НАЦИОНАЛЬНОЙ АКАДЕМИИ НАУК АРМЕНИИ
}

Utikuminluw

72, №1, 2019

Механика

\section{AXISYMMETRIC STABILITY OF CIRCULAR RING PLATE SUBJECTED TO MECHANICAL AND THERMAL LOADS Avetisyan A.S., Aleksanyan R.K., Aleksanyan D.R.}

Keywords: circular ring plate, elastic stability, boundary load, critical value, plate deflection.

Аветисян А.С., Алексанян Р.К., Алексанян Д.Р.

Осесимметричная устойчивость круглой кольцевой плиты, подверженной механическим и термическим нагрузкам

Ключевые слова: круглая кольцевая пластина, упругая устойчивость, предельная нагрузка, критическое значение, прогиб.

Исследована возможность потери осесимметричной устойчивости круглой кольцевой пластины, подвергнутого воздействию равномерно изменяющегося по радиусу кольца теплового поля. Внутренная кромка кольца зажата или подвержена воздействию внешних механических сил. На внешнем крае круглого кольца равномерно распределенние силы действуют как растягивающая или сжимающая нагрузки. С учетом сформированного плоского напряженного состояния в круговом кольце для всех случаев внутренних напряжений в зонах сжатия определены значения продольного смещения. В случае общей нагрузки кольца напряжения выражаются как функциями Бесселя первого и второго порядка, так и цилиндрической функцией мнимых аргументов с действительными индексами. В некоторых частных случаях нагружения колец, уравнения устойчивости пластины перестраиваются в уравнения типа Эйлера, а напряжения в пластине выражаются через элементарные функции.

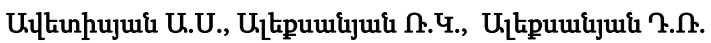

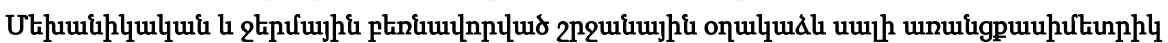
qujnıinıpjnıip

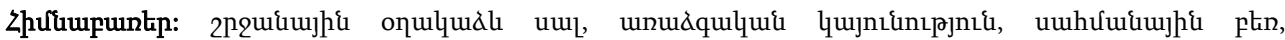

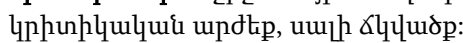

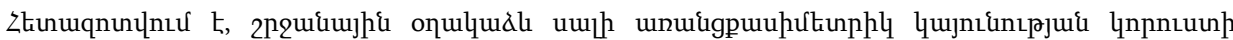

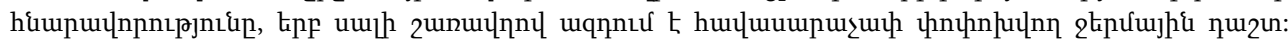

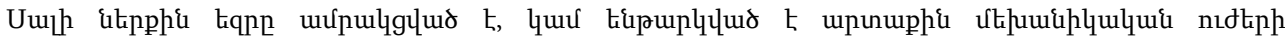

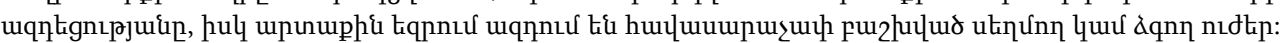

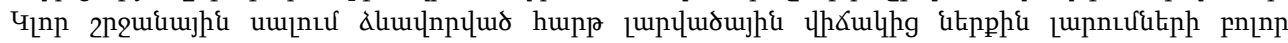

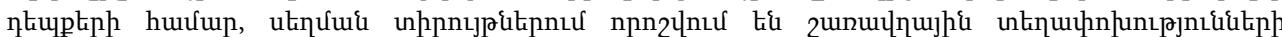

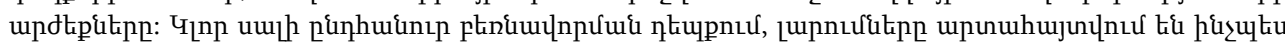

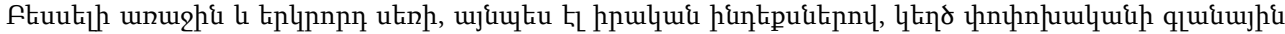

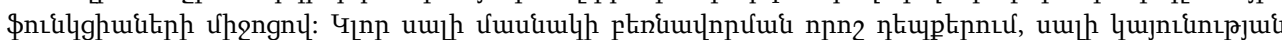

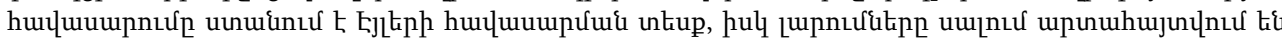

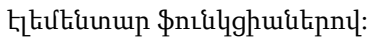

The possibility of loss of the axisymmetric stability of a circular ring plate is investigated, when uniformly varying thermal field impacts over plate radius. The inner border of the plate is clamped or is exposed to the impact of external mechanical forces. Uniformly distributed tensile or compressive forces impact at the outer border of the plate. Taking into account the formed flat stress state in the circular ring plate, the values of the longitudinal displacements are determined for all cases of internal stresses in the compression zones. In the case of the general loading of the ring plate, the stresses are expressed by both first-order and second-order Bessel's functions, as well as by cylindrical functions of imaginary arguments with real indices. In the cases of ring plate 
partial loading, the equations of plate stability get the look of Euler type equations, and the stresses in the plate are expressed by elementary functions.

\section{Introduction}

The problem of circular ring plate stability subjected to the compressive forces at the mid-plane first time was investigated in [1]. The problem of axisymmetric stability loss of the circular ring plate subjected to the uniformly distributed compressive forces is considered in [2]. The general case of the above-mentioned problem is in paper [3]. The investigations of the problems of axisymmetric and non-axisymmetric stability of ring plate have been done in $[4,5]$ for two different cases: a) the circular ring plate is subjected to the uniformly distributed compressive forces along the outer border of the plate; $b$ ) the circular ring plate is subjected to the uniformly distributed tensile (radial) forces along the inner border of the plate.

The generalized problem of stability of the circular ring plate subjected to the uniformly distributed tensile and compressive (radial) forces along the outer and inner borders is considered in [6]. In this article, the various cases of boundary conditions are satisfied taking into account the longitudinal displacements determined from the formulas of plate stability problem. Equations of critical values of unknown parameters are received from the conditions of non-zero solution of the homogeneous equations' system for integration constants.

In technical report [7], an analysis of the stability of circular ring plates under uniformly distributed radial load is presented. It was found that, in general, the critical mode shapes are combinations of in- and out-of-plane displacements and they occur when loads considerably are below the classical (in-plane) critical load. In paper [8], the stability of circular ring plate, pre-stressed by temperature-like intrinsic deformation, is studied using the equations of the nonlinear theory of rods. The temperature gradient in the radial direction results in a bending moment. The analytical solutions are successfully compared against results of finite element simulations for a shell model of the ring.

In papers $[9,10]$ the linearized problems on the stability of a circular ring sandwich of symmetric structure under axially symmetric temperature field, inhomogeneous through the core thickness, are stated and their analytical solutions are given. The deformation processes for the load-carrying layers are described by the Kirchhoff-Love model. For the core of arbitrary thickness, the deformation process is described - by two models, namely by the equations of the plane problem of elasticity theory and by the model of a transversely soft layer of arbitrary thickness.

\section{The problem statement. Plane stress state of circular ring plate.}

Let us consider a circular ring plate with the thickness $h$, which is clamped at the inner border $r=b$, and is subjected to the tensile or compressive uniformly distributed load with intensity $P$ at outer border $r=a$. The plate is also exposed to uniformly varying temperature along radius of the ring plate. The plane stress state of axisymmetric circular 
ring plate is characterized by the direction of radius via the non-zero component of displacement $\boldsymbol{u}$ at the middle plane of the plate [11].

$u_{r}=C_{1} r+\frac{C_{2}}{r}, \quad b \leq r \leq a$

Corresponding to the arising internal stresses $\sigma_{r}$ and $\sigma_{\theta}$, the arising at the circular ring plate internal efforts $N_{r}(r), N_{\theta}(r)$ and $N_{r \theta}(r)$ are determined by the following formulas

$$
\begin{aligned}
& N_{r}(r)=\frac{E h}{1-v^{2}}\left[\frac{d u_{r}}{d r}+v \frac{u_{r}}{r}-(1+v) \alpha T\right] \\
& N_{\theta}(r)=\frac{E h}{1-v^{2}}\left[\frac{u_{r}}{r}+v \frac{d u_{r}}{d r}-(1+v) \alpha T\right] \\
& N_{r \theta}(r) \equiv 0 .
\end{aligned}
$$

Here, $E$ is the modulus of elasticity, $v$ is the Poisson's ratio, $\alpha$ is the coefficient of thermal expansion, $T$ is the temperature change correspondingly for a plate material. Based on (1.1) and (1.2), as well as satisfying the boundary conditions on the edge of the circular ring plate

$\left.u\right|_{r=b}=0,\left.\quad N_{r}\right|_{r=a}=p$,

we obtain the following relations for the cutting forces:

$$
\begin{aligned}
& N_{r}(r)=\frac{E h}{(1+v) \delta}\left[P_{0}\left(1+\frac{b^{2} v^{*}}{r^{2}}\right)+\alpha T l^{2}\left(\frac{a^{2}}{r^{2}}-1\right)\right], \\
& N_{\theta}(r)=\frac{E h}{(1+v) \delta}\left[P_{0}\left(1-\frac{b^{2} v^{*}}{r^{2}}\right)-\alpha T l^{2}\left(\frac{a^{2}}{r^{2}}+1\right)\right] .
\end{aligned}
$$

Here, $\quad v^{*}=(1-v) /(1+v), \quad \delta=1+v^{*} l^{2}, \quad P_{0}=P(1+v) / E h, \quad$ and $l=b / a \quad$ are dimensionless parameters of the circular ring plate.

If either tensile or compressive forces $(P>0$ or $P<0)$ impact on the outer border of the circular ring plate and either steady increase or steady decrease of temperature ( $T>0$ or $T<0$ ) is influencing the thermal expansion of the circular ring plate, the forces defined by equation (1.4) on the plane of the circular ring plate can be tensile or compressive, i.e. the strips (zones) of tension or compression forces are located on the circular ring plate. For any force, the presence of compressive zone is pointing out the lost of stability of the circular ring plate. Therefore, if $P_{0}>0$ and $T>0$ then $N_{r}>0$ for $r \in[b ; a]$, meanwhile $N_{\theta}$ for $[b ; a]$ can have a compressive zone. Furthermore, if $P_{0}<0$ and $T<0$ then $N_{r}<0$ for $r \in[b ; a]$, meanwhile $N_{\theta}$ can change the sign. 
Similar to the above-mentioned consideration, it is easy to prove that for $P_{0}$ and $T$ having opposite signs, $N_{r}$ and $N_{\theta}$ in the interval $[b ; a]$ can contain compressive zones. Consequently, in any case, the circular ring plate can lose the stability.

The forces defined by formula (1.4) can be expressed as follows:

$$
N_{r ; \theta}(r)=\frac{E h}{(1+v) \delta}\left[\left(P_{0}-\alpha T l^{2}\right) \pm\left(P_{0} v^{*}+\alpha T\right) \frac{b^{2}}{r^{2}}\right]
$$

\section{The problem of stability lost of axisymmetric circular ring plate}

In the problem of stability lost of the axisymmetric circular ring plate losing its stability, the deflection $\mathrm{w}(r)$ satisfies to the following equation [2-6]

$$
D \Delta \Delta \mathrm{w}(r)=N_{r} \frac{d^{2} \mathrm{w}(r)}{d r^{2}}+N_{\theta} \frac{1}{r} \frac{d \mathrm{w}(r)}{d r},
$$

where $D=E h^{3} / 12\left(1-v^{2}\right)$ is cylindrical flexural rigidity of the circular ring plate, and $\Delta(\circ)=\left(d^{2} / d r^{2}\right)+(1 / r) \cdot(d / d r)$ is a one-dimensional differential operator.

Based on expressions (1.5), the equation (2.1) can be expressed in the following way:

$$
\Delta \Delta \mathrm{w}(r)=\frac{E h\left(P_{0}-\alpha T l^{2}\right)}{D(1+v) \delta}\left[\left(1 \pm \frac{\gamma^{2} b^{2}}{r^{2}}\right) \frac{d^{2} \mathrm{w}(r)}{d r^{2}}+\left(1 \mp \frac{\gamma^{2} b^{2}}{r^{2}}\right) \frac{1}{r} \frac{d \mathrm{w}(r)}{d r}\right]
$$

where "+" sign should be chosen for the values $\left(P_{0}-\alpha T l^{2}\right)$ and $\left(P_{0} v^{*}+\alpha T\right)$ having the same sign; "-" sign should be chosen for the values having opposite signs, and $\gamma^{2}=\left|P_{0} v^{*}+\alpha T\right| /\left|P_{0}-\alpha T l^{2}\right|$.

The following status options of equation (2.2) determining for $\mathrm{w}(r)$ are considered:

I. if $P_{0}-\alpha T l^{2}>0$, and $P_{0} v^{*}+\alpha T>0$ then

$$
\Delta \Delta \mathrm{w}(r)-\beta^{2}\left[\left(1+\frac{\gamma^{2} b^{2}}{r^{2}}\right) \frac{d^{2} \mathrm{w}(r)}{d r^{2}}+\left(1-\frac{\gamma^{2} b^{2}}{r^{2}}\right) \frac{1}{r} \frac{d \mathrm{w}(r)}{d r}\right]=0 .
$$

II. if $P_{0}-\alpha T l^{2}>0$ and $P_{0} v^{*}+\alpha T<0$ then

$$
\Delta \Delta \mathrm{w}(r)-\beta^{2}\left[\left(1-\frac{\gamma^{2} b^{2}}{r^{2}}\right) \frac{d^{2} \mathrm{w}(r)}{d r^{2}}+\left(1+\frac{\gamma^{2} b^{2}}{r^{2}}\right) \frac{1}{r} \frac{d \mathrm{w}(r)}{d r}\right]=0 .
$$

where $\beta^{2}=12(1-v)\left(P_{0}-\alpha T l^{2}\right) / h^{2} \delta$.

III. if $P_{0}-\alpha T l^{2}<0$ and $P_{0} v^{*}+\alpha T<0$ then

$$
\Delta \Delta \mathrm{w}(r)+\beta_{1}^{2}\left[\left(1+\frac{\gamma^{2} b^{2}}{r^{2}}\right) \frac{d^{2} \mathrm{w}(r)}{d r^{2}}+\left(1-\frac{\gamma^{2} b^{2}}{r^{2}}\right) \frac{1}{r} \frac{d \mathrm{w}(r)}{d r}\right]=0 .
$$


IV. if $P_{0}-\alpha T l^{2}<0$ and $P_{0} v^{*}+\alpha T>0$ then

$$
\Delta \Delta \mathrm{w}(r)+\beta_{1}^{2}\left[\left(1-\frac{\gamma^{2} b^{2}}{r^{2}}\right) \frac{d^{2} \mathrm{w}(r)}{d r^{2}}+\left(1+\frac{\gamma^{2} b^{2}}{r^{2}}\right) \frac{1}{r} \frac{d \mathrm{w}(r)}{d r}\right]=0,
$$

where $\beta_{1}^{2}=12(1-v)\left|P_{0}-\alpha T l^{2}\right| / h^{2} \delta$.

It is evident that here the following limiting cases are possible.

1. In case of $P_{0}-\alpha T l^{2}=0$ and $P_{0} v^{*}+\alpha T \neq 0$, the equation (2.1) can be expressed as follows

$\Delta \Delta \mathrm{w}(r)-H^{2}\left(\frac{1}{r^{2}} \frac{d^{2} \mathrm{w}(r)}{d r^{2}}-\frac{1}{r^{2}} \frac{d \mathrm{w}(r)}{d r}\right)=0$, for $P_{0} v^{*}+\alpha T>0$,

where $H^{2}=12(1-v) b^{2}\left(P_{0} v^{*}+\alpha T\right) / h^{2} \delta$, and as follows

$\Delta \Delta \mathrm{w}(r)+\bar{H}^{2}\left(\frac{1}{r^{2}} \frac{d^{2} \mathrm{w}(r)}{d r^{2}}-\frac{1}{r} \frac{d \mathrm{w}(r)}{d r}\right)=0$, for $P_{0} v^{*}+\alpha T<0$,

where $\bar{H}^{2}=12(1-v) b^{2}\left|P_{0} v^{*}+\alpha T\right| / h^{2} \delta$.

2. In the case of $P_{0}-\alpha T l^{2} \neq 0$ and $P_{0} v^{*}+\alpha T=0$ : if $P_{0}-\alpha T l^{2}>0$ then $N_{r}=N_{\theta}=E h\left(P_{0}-\alpha T l^{2}\right) / \delta(1+v)>0$, in $r \in[a, b]$. Therefore, the plate is subjected to all-around tension; meanwhile, the plate doesn't lose the stability.

3. If $P_{0}-\alpha T l^{2}<0$ and $P_{0} v^{*}+\alpha T=0$ then $N_{r}=N_{\theta}=E h\left(P_{0}-\alpha T l^{2}\right) /(1+v) \delta<0$. In this case, the circular ring plate is subjected to all-around compression. Consequently, the circular ring plate can lose the stability [12]. For this purpose, the equation (2.1) should be expressed as follows

$\Delta \Delta \mathrm{w}+H_{1}^{2} \Delta \mathrm{w}=0$, where $H_{1}^{2}=12(1-v)\left|P_{0}-\alpha T l^{2}\right| /(1+v) \delta$

4. If $P_{0}-\alpha T l^{2}=0$ and $P_{0} v^{*}+\alpha T=0$ then $P_{0}=0$ and $\alpha T=0$.

In this case, the circular ring plate is free from external mechanical and thermal actions and it will by stabile.

\section{Integration of stability equations of the circular ring plate.}

Replacing variables $X=\beta \cdot r$, equations (2.3) and (2.4) can be expressed as follows:

$\Delta_{x} \Delta_{x} \mathrm{w}(x)-\left[\left(1+\frac{d^{2} \beta^{2}}{x^{2}}\right) \frac{d^{2} \mathrm{w}(x)}{d x^{2}}+\left(1-\frac{d^{2} \beta^{2}}{x^{2}}\right) \frac{1}{x} \frac{d \mathrm{w}(x)}{d x}\right]=0$, 
$\Delta_{x} \Delta_{x} \mathrm{w}(x)-\left[\left(1-\frac{d^{2} \beta^{2}}{x^{2}}\right) \frac{d^{2} \mathrm{w}(x)}{d x^{2}}+\left(1+\frac{d^{2} \beta^{2}}{x^{2}}\right) \frac{1}{x} \frac{d \mathrm{w}(x)}{d x}\right]=0$,

where $d^{2}=\gamma^{2} b^{2}, \Delta_{x}=\left(d^{2} / d x^{2}\right)+(1 / x)(d / d x)$ - is a one-dimensional differential operator. If denote $z(x)=d \mathrm{w}(x) / d x$, the equations (3.1) and (3.2) can be represented as follows:

$$
\begin{aligned}
& x\left[x^{2} z^{\prime \prime}+x z^{\prime}-\left(\eta_{1}^{2}+x^{2}\right) z\right]^{\prime}-\left[x^{2} z^{\prime \prime}+x z^{\prime}-\left(\eta_{1}^{2}+x^{2}\right) z\right]=0, \\
& x\left[x^{2} z^{\prime \prime}+x z^{\prime}-\left(\eta_{2}^{2}+x^{2}\right) z\right]^{\prime}-\left[x^{2} z^{\prime \prime}+x z^{\prime}-\left(\eta_{2}^{2}+x^{2}\right) z\right]=0,
\end{aligned}
$$

where $\eta_{1,2}^{2}=1 \pm d^{2} \beta^{2}$.

Integrating equations (3.3) and (3.4), the following equations can be obtained:

$$
\begin{aligned}
& x^{2} z^{\prime \prime}+x z^{\prime}-\left(\eta_{1}^{2}+x^{2}\right) z=C x, \\
& x^{2} z^{\prime \prime}+x z^{\prime}-\left(\eta_{2}^{2}+x^{2}\right) z=\bar{C} x,
\end{aligned}
$$

here $C$ and $\bar{C}$ are integration constants. The solution of equations (3.5) and (3.6) should be determined by the following expressions.

$$
\begin{aligned}
& z=C_{1}(x) I_{\eta_{1}}(x)+C_{2}(x) K_{\eta_{1}}(x) \\
& z=E_{1}(x) I_{\eta_{2}}(x)+E_{2}(x) K_{\eta_{2}}(x)
\end{aligned}
$$

where $I_{\eta}(x)$ and $K_{\eta}(x)$ are the cylindrical function of imaginary arguments with the real indexes; $C_{i}(x), E_{i}(x)(i=1,2)$ are arbitrary functions defined by the variation method of arbitrary constants.

The solutions of equations (3.5) and (3.6) can be expressed as follows:

$$
\begin{aligned}
& z=\overline{C_{1}} I_{\eta_{1}}(x)+\overline{C_{2}} K_{\eta_{1}}(x)+C f_{1}(x) \\
& z=\overline{E_{1}} I_{\eta_{2}}(x)+\overline{E_{2}} K_{\eta_{2}}(x)+\bar{C} f_{2}(x)
\end{aligned}
$$

The corresponding deflections can be defined by the following equations:

$$
\begin{aligned}
& \left.\mathrm{w}(x)=\int \overline{\left[C_{1}\right.} I_{\eta_{1}}(x)+\overline{C_{2}} K_{\eta_{1}}(x)\right] d x+C \int f_{1}(x) d x+H_{1} \\
& \mathrm{w}(x)=\int\left[\overline{E_{1}} I_{\eta_{2}}(x)+\overline{E_{2}} K_{\eta_{2}}(x)\right] d x+\bar{C} \int f_{2}(x) d x+H_{2}
\end{aligned},
$$

where $\bar{C}_{i} ; \bar{E}_{i} ; \bar{H}_{i}(i=1,2)$ are integration constants, and

$$
f_{i}(x)=I_{\eta_{i}}(x) \int K_{\eta_{i}}(x) d x-K_{\eta_{i}}(x) \int I_{\eta_{i}}(x) d x \quad(i=1,2) .
$$

Denoting $X_{1}=\beta_{1} r$, equations (2.5) and (2.6) can be represented as follows: 
$\Delta_{x} \Delta_{x} \mathrm{w}\left(x_{1}\right)+\left(1+\frac{d^{2} \beta_{1}^{2}}{x_{1}^{2}}\right) \frac{d^{2} \mathrm{w}\left(x_{1}\right)}{d x_{1}^{2}}+\left(1-\frac{d^{2} \beta_{1}^{2}}{x_{1}^{2}}\right) \frac{1}{x_{1}} \frac{d \mathrm{w}\left(x_{1}\right)}{d x_{1}}=0$,

$\Delta_{x} \Delta_{x} \mathrm{w}\left(x_{1}\right)+\left(1-\frac{d^{2} \beta_{1}^{2}}{x_{1}^{2}}\right) \frac{d^{2} \mathrm{w}\left(x_{1}\right)}{d x_{1}^{2}}+\left(1+\frac{d^{2} \beta_{1}^{2}}{x_{1}^{2}}\right) \frac{1}{x_{1}} \frac{d \mathrm{w}\left(x_{1}\right)}{d x_{1}}=0$.

The integration of equations (3.10) and (3.11) can be reduced to the integration of Bessel's non-homogeneous equations.

$x_{1}^{2} z^{\prime \prime}+x_{1} z^{\prime}-\left(\xi_{1}^{2}-x_{1}^{2}\right) z=C_{0} x_{1}$,

$x_{1}^{2} z^{\prime \prime}+x_{1} z^{\prime}-\left(\xi_{2}^{2}-x_{1}^{2}\right) z=\bar{C}_{0} x_{1}$,

where $z\left(x_{1}\right)=d \mathrm{w}\left(x_{1}\right) / d x_{1}, C_{0}, \bar{C}_{0}$ are integration constants.

The generalized solutions of equations (3.12) are the following

$z\left(x_{1}\right)=\bar{E}_{1} J_{\xi_{1}}\left(x_{1}\right)+\bar{E}_{2} Y_{\xi_{1}}\left(x_{1}\right)+\left(\pi C_{0} / 2\right) \phi_{1}\left(x_{1}\right)$

$z\left(x_{1}\right)=\bar{H}_{1} J_{\xi_{2}}\left(x_{1}\right)+\bar{H}_{2} Y_{\xi_{2}}\left(x_{1}\right)+\left(\pi \bar{C}_{0} / 2\right) \phi_{2}\left(x_{1}\right)$

The corresponding deflections can be obtained from the following relations

$$
\begin{aligned}
& \mathrm{w}\left(x_{1}\right)=\int\left[\overline{E_{1}} J_{\xi_{1}}\left(x_{1}\right)+\overline{E_{2}} Y_{\xi_{1}}\left(x_{1}\right)\right] d x_{1}+\frac{\pi C_{0}}{2} \int \phi_{1}\left(x_{1}\right) d x_{1}+E_{0}, \\
& \mathrm{w}\left(x_{1}\right)=\int\left[\overline{H_{1}} J_{\xi_{2}}\left(x_{1}\right)+\overline{H_{2}} Y_{\xi_{2}}\left(x_{1}\right)\right] d x_{1}+\frac{\pi \overline{C_{0}}}{2} \int \phi_{2}\left(x_{1}\right) d x_{1}+H_{0},
\end{aligned}
$$

where $J_{\xi}\left(x_{1}\right)$ and $Y_{\xi}(x)$ are the first-order and the second-order Bessel's functions; $\bar{E}_{i}, \bar{H}_{i}, E_{0}, H_{0}(i=1,2)$ are integration constants; and

$\phi_{i}\left(x_{1}\right)=Y_{\xi i}\left(x_{1}\right) \int J_{\xi i}\left(x_{1}\right) d x_{1}-J_{\xi i}\left(x_{1}\right) \int Y_{\xi i}\left(x_{1}\right) d x_{1}(i=1,2)$.

For the first limiting case $\left(P_{0}-\alpha T l^{2}=0, \quad P_{0} v^{*}+\alpha T \neq 0\right)$ and $P_{0} v^{*}+\alpha T>0$, the force $\mathrm{w}\left(x_{1}\right)$ is obeying equation (2.7). Meanwhile, for $P_{0} v^{*}+\alpha T<0$, the force $\mathrm{w}\left(x_{1}\right)$ is obeying equation (2.8). The equation (2.7) is an equation of Eulerian kind:

$\mathrm{w}^{I V}+\frac{2}{r} \mathrm{w}^{I I I}-\left(1+H^{2}\right) \frac{1}{r^{2}} \mathrm{w}^{I I}+\left(1+H^{2}\right) \frac{1}{r^{3}} \mathrm{w}^{I}=0$,

where $H^{2}=12(1-v) b^{2}\left(P_{0} v^{*}+\alpha T\right) / h^{2}\left(1+v^{*} l^{2}\right)$.

Denoting $x=r / a, l \leq x \leq 1, l=b / a$, equation (3.15) can be represented as follows:

$x^{3} \mathrm{w}^{I V}+2 x^{2} \mathrm{w}^{I I I}-x\left(1+H^{2}\right) \mathrm{w}^{I I}+\left(1+H^{2}\right) \mathrm{w}^{I}=0$.

The generalized solution of eq. (3.16) is the following 
$\mathrm{w}(x)=C_{1}+C_{2} x^{2}+C_{3} x^{1+k}+C_{4} x^{1-k}$,

where $k=\sqrt{1+H^{2}}$.

In case of $P_{0} v^{*}+\alpha T<0$, the equation (2.8) can be represented as follows

$x^{3} \mathrm{w}^{I V}(x)+2 x^{2} \mathrm{w}^{I I I}(x)-x\left(1-\bar{H}^{2}\right) \mathrm{w}^{I I}+\left(1-\bar{H}^{2}\right) \mathrm{w}^{I}(x)=0$,

where $\bar{H}^{2}=12(1-v) b^{2}\left|P_{0} v^{*}+\alpha T\right| / h^{2}\left(1+v^{*} l^{2}\right)$

In the case of $1-\bar{H}^{2}>0$, the deflection can be written using the generalized solution of equation (3.18)

$\mathrm{w}(x)=B_{1}+B_{2} x^{2}+B_{3} x^{1+k}+B_{4} x^{1-k}$.

Similarly, in the case of $1-\bar{H}^{2}<0$, the corresponding solution of equation (3.18) can be obtained as

$\mathrm{w}(x)=D_{1}+D_{2} x^{2}+x \cdot\left[D_{3} \cos (\beta \ln x)+D_{4} \sin (\beta \ln x)\right]$,

where $\beta^{2}=\bar{H}^{2}-1$.

For $1-\bar{H}^{2}=0$, deflections can be defined as $\mathrm{w}(x)=C_{1} x \cdot \ln x+C_{2} x^{2}+C_{3} x+C_{4}$.

For the second limiting case $P_{0}-\alpha T l^{2} \neq 0$ and $P_{0} v^{*}+\alpha T=0$, the circular ring plate can lose its stability, if $P_{0}-\alpha T l^{2}<0$. For this case, the deflection can be determined by equation (2.9). Replacing variables $\rho=r / a, l \leq \rho \leq 1$, equation (2.9) can be represented as follows [12]:

$\Delta_{\rho} \Delta_{\rho} \mathrm{W}(x)+k^{2} \Delta_{\rho} \mathrm{W}(x)=0$,

Where $k^{2}=12 a^{2}(1-v)\left|P_{0}-\alpha T l^{2}\right| / h^{2}\left(1+v^{*} l^{2}\right)$,

$\Delta_{\rho}=d^{2} / d \rho^{2}+(1 / \rho)(d / d \rho)$,

Denoting $x=k \rho$, the following equation is obtained:

$\Delta_{x} \Delta_{x} \mathrm{~W}(x)+\Delta_{x} \mathrm{~W}(x)=0$.

Meanwhile, denoting $w^{\prime}=z$, the following equation is obtained:

$x\left[x^{2} z^{\prime \prime}(x)+x z^{\prime}(x)-\left(1-x^{2}\right) z(x)\right]^{\prime}-\left[x^{2} z^{\prime \prime}(x)+x z^{\prime}(x)-\left(1-x^{2}\right) z(x)\right]=0$.

Integrating the last equation, the following equation is obtained:

$x^{2} z^{\prime \prime}(x)+x z^{\prime}(x)-\left(1-x^{2}\right) z(x)=C_{0} x$,

where $C_{0}$ is an integration constant.

The generalized solution of equation (3.24) can be defined in the following way: $z(x)=A_{1} J_{1}(x)+B_{1} Y_{1}(x)+C_{0} / x$. 
Taking into account $z(x)=d \mathrm{w}(x) / d x$ and integrating eq. (3.25), the following equation can be obtained:

$\mathrm{w}(x)=A_{0} J_{0}(x)+B_{0} Y_{0}(x)+C_{0} \ln x+D_{0}$,

where $A_{0}, B_{0}, C_{0}$, and $D_{0}$ are integration constants.

\section{Determination of parameters critical values}

Longitudinal displacements defined by the integration of stability equations of the circular ring plate should satisfy the boundary conditions on the plate borders.

In practice, the following cases of boundary conditions are considered (Figure 1. : Figure 4.)

1.

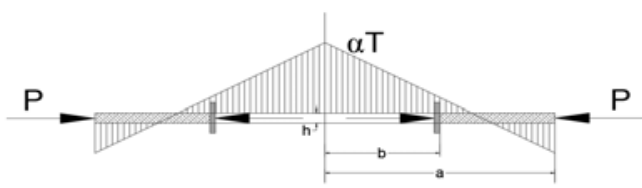

Figure 1. The internal border of the plate $r=b$ is clamped, and the external border of the plate $r=a$ is free

with the following boundary conditions,

$\left.\mathrm{W}\right|_{r=b}=0,\left.\quad \frac{d \mathrm{w}}{d r}\right|_{r=b}=0,\left.\quad M_{r}\right|_{r=a}=0,\left.\quad Q_{r}\right|_{r=a}=0$

2.

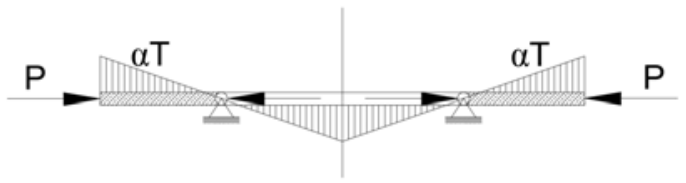

Figure 2. The internal border of the plate $r=b$ is hinged, and the external border of the plate $r=a$ is free.

with the following boundary conditions,

$\left.\mathrm{W}\right|_{r=b}=0,\left.\quad M_{r}\right|_{r=b}=0,\left.\quad M_{r}\right|_{r=a}=0,\left.\quad Q_{r}\right|_{r=a}=0$ 
3.

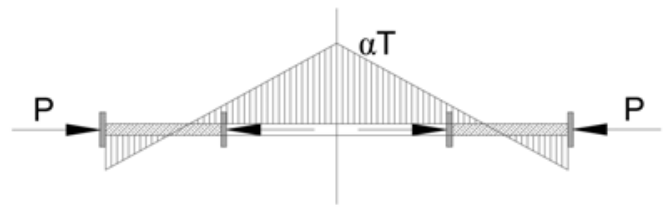

Figure 3. The borders of the plate are clamped.

with the following boundary conditions,

$\left.\mathrm{w}\right|_{r=b}=0,\left.\quad \frac{d \mathrm{w}}{d r}\right|_{r=b}=0,\left.\quad \mathrm{w}\right|_{r=a}=0,\left.\quad \frac{d \mathrm{w}}{d r}\right|_{r=a}=0$

4.

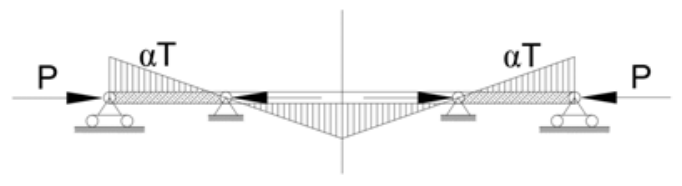

Figure 4. The borders of the plate are hinged

with the following boundary conditions,

$\left.\mathrm{W}\right|_{r=b}=0,\left.\quad M_{r}\right|_{r=b}=0,\left.\quad M_{r}\right|_{r=a}=0,\left.\quad \mathrm{~W}\right|_{r=a}=0$

In the problem of axisymmetric stability of the plate, bending moments and cutting forces through forces $\mathrm{w}(r)$ can be defined by the following equations:

$M_{r}=-D\left(\frac{d^{2} \mathrm{w}}{d r^{2}}+\frac{v}{r} \frac{d \mathrm{w}}{d r}\right), \quad Q_{r}=-D \frac{d}{d r}(\Delta \mathrm{w})$, or

$M_{r}=-D \beta^{2}\left(\frac{d^{2} \mathrm{w}}{d x^{2}}+\frac{v}{x} \frac{d \mathrm{w}}{d x}\right)=-\frac{D \beta^{2}}{x}\left(x z^{\prime}+v z\right) ;$

$Q_{r}=-D \beta^{2} \frac{d}{d x}\left(\frac{d^{2} \mathrm{w}}{d x^{2}}+\frac{1}{x} \frac{d \mathrm{w}}{d x}\right)=-\frac{D \beta^{2}}{x}\left(x^{2} z^{\prime \prime}+x z^{\prime}-z\right) ; x=\beta r \frac{\delta y}{\delta x}$.

In the view of the determination of critical values of parameters, let's consider the fourth option $\left(P_{0}-\alpha T l^{2}<0, P_{0} v^{*}+\alpha T>0\right)$. In this case, from equations (3.13) and (3.14), $z=\mathrm{w}^{\prime}\left(x_{1}\right)$ and $\mathrm{w}\left(x_{1}\right)$ can be expressed as follows: 


$$
\begin{aligned}
& z\left(x_{1}\right)=\bar{H}_{1} J_{\xi_{2}}\left(x_{1}\right)+\bar{H}_{2} Y_{\xi_{2}}\left(x_{1}\right)+\frac{\pi \bar{C}_{0}}{2} \phi_{2}\left(x_{1}\right) ; \\
& \mathrm{w}\left(x_{1}\right)=\int_{\beta_{1} b}^{x_{1}}\left[\bar{H}_{1} J_{\xi_{2}}\left(x_{1}\right)+\bar{H}_{2} Y_{\xi_{2}}\left(x_{1}\right)+\frac{\pi \bar{C}_{2}}{2} \phi_{2}\left(x_{1}\right)\right] d x_{1}+\bar{H}_{0},
\end{aligned}
$$

Where $x_{1}=\beta_{1} r, \quad \xi_{2}=\beta^{2}{ }_{1} d^{2}, \quad d^{2}=\gamma^{2} b^{2}, \quad \beta_{1} d \leq x_{1} \leq \beta_{1} a$, and

$\phi_{2}\left(x_{1}\right)=-J_{\xi_{2}}\left(x_{1}\right) \int_{\beta_{1} b}^{x_{1}} Y_{\xi_{2}}(x) d x+Y_{\xi_{2}}\left(x_{1}\right) \int_{\beta_{1} b}^{x_{1}} J_{\xi_{2}}(x) d x$

Satisfying the boundary conditions (4.1) and based on equations (4.6) - (4.7), we can receive the following system of equations:

$$
\left\{\begin{array}{l}
H_{0}=0 \\
\bar{H}_{1} J_{\xi_{2}}\left(\beta_{1} b\right)+\bar{H}_{2} Y_{\xi_{2}}\left(\beta_{1} b\right)=0 \\
\bar{H}_{1} J_{\xi_{2}}\left(\beta_{1} a\right)+\bar{H}_{2} Y_{\xi_{2}}\left(\beta_{1} a\right)+ \\
+\frac{\pi \overline{C_{0}}}{2}\left[-J_{\xi_{2}}\left(\beta_{1} a\right) \int_{\beta_{1} b}^{\beta_{1} a} Y_{\xi_{2}}(x) d x+Y_{\xi_{2}}\left(\beta_{1} a\right) \int_{\beta_{1} b}^{\beta_{1} a} J_{\xi_{2}}(x) d x\right]-\frac{\bar{C}_{0}}{\beta_{1} a\left(1-\gamma^{2} l^{2}\right)}=0 \\
\bar{H}_{1} J_{\xi_{2}}^{\prime}\left(\beta_{1} a\right)+\bar{H}_{2} Y_{\xi_{2}}^{\prime}\left(\beta_{1} a\right)+ \\
+\frac{\pi \bar{C}_{0}}{2}\left[-J_{\xi_{2}}^{\prime}\left(\beta_{1} a\right) \int_{\beta_{1} b}^{\beta_{1} a} Y_{\xi_{2}}(x) d x+Y_{\xi_{2}}^{\prime}\left(\beta_{1} a\right) \int_{\beta_{1} b}^{\beta_{1} a} J_{\xi_{2}}(x) d x\right]+\frac{v \bar{C}_{0}}{\beta^{2} a^{2}\left(1-\gamma^{2} l^{2}\right)}=0
\end{array}\right.
$$

For the boundary condition (4.2), the following system of equations can be obtained:

$$
\left\{\begin{array}{l}
\bar{H}_{0}=0 \\
{\left[J_{\xi_{2}}^{\prime}\left(\beta_{1} b\right)+v J_{\xi_{2}}\left(\beta_{1} b\right)\right] \bar{H}_{1}+\left[Y_{\xi_{2}}^{\prime}\left(\beta_{1} b\right)+v Y_{\xi_{2}}\left(\beta_{1} b\right)\right] \bar{H}_{2}=0} \\
\bar{H}_{1} J_{\xi_{2}}^{\prime}\left(\beta_{1} a\right)+\bar{H}_{2} Y_{\xi_{2}}^{\prime}\left(\beta_{1} a\right)+ \\
+\frac{\pi \bar{C}_{0}}{2}\left[-J_{\xi_{2}}^{\prime}\left(\beta_{1} a\right) \int_{\beta_{1} b}^{\beta_{1} a} Y_{\xi_{2}}(x) d x+Y_{\xi_{2}}^{\prime}\left(\beta_{1} a\right) \int_{\beta_{1} b}^{\beta_{1} a} J_{\xi_{2}}(x) d x\right]+\frac{v \bar{C}_{0}}{\beta_{1}^{2} a^{2}\left(1-\gamma^{2} l^{2}\right)}=0 \\
\bar{H}_{1} J_{\xi_{2}}\left(\beta_{1} a\right)+\bar{H}_{2} Y_{\xi_{2}}\left(\beta_{1} a\right)+ \\
+\frac{\pi \bar{C}_{0}}{2}\left[-J_{\xi_{2}}\left(\beta_{1} a\right) \int_{\beta_{1} b}^{\beta_{1} a} Y_{\xi_{2}}(x) d x+Y_{\xi_{2}}\left(\beta_{1} a\right) \int_{\beta_{1} b}^{\beta_{1} a} J_{\xi_{2}}(x) d x\right]-\frac{\bar{C}_{0}}{\beta_{1} a\left(1-\gamma^{2} l^{2}\right)}=0
\end{array}\right.
$$

Based on the existence condition of non-zero solution of the system of homogeneous equations for the integration constants obtained by equations (4.8) and (4.9), the transcendent equation for any random parameter can be determined taking into account that the rest of parameters have received specified values. 
For the first limiting case $\left(P_{0}-\alpha T l^{2}=0, P_{0} v^{*}+\alpha T \neq 0\right)$, the force $\mathrm{w}(x)$ can be obtained by equations (3.17) and (3.19) in case of $P_{0} v^{*}-\alpha T l^{2}<0$. Determining the force $\mathrm{w}(x)$ by equation (3.19) and satisfying the boundary conditions (4.3), for the determination of integration parameters $B_{i}$ the following system of homogeneous equations will be received.

$$
\left\{\begin{array}{l}
B_{1}+B_{2} l^{2}+B_{3} l^{1+\bar{k}}+B_{4} l^{1-\bar{k}}=0 \\
2 l B_{2}+B_{3}(1+\bar{k}) l^{\bar{k}}+B_{4}(1-\bar{k}) l^{-k}=0 \\
B_{1}+B_{2}+B_{3}+B_{4}=0 \\
2 B_{2}+(1+\bar{k}) B_{3}+(1-\bar{k}) B_{4}=0
\end{array}\right.
$$

Taking into account that

$\left\{\begin{array}{l}P_{0}-\alpha T l^{2}=0 \\ P_{0} v^{*}+\alpha T<0\end{array} \quad\left\{\begin{array}{l}P_{0}=\alpha T l^{2} \\ \alpha T\left(1+v^{*} l^{2}\right)>0\end{array} \Rightarrow\left\{\begin{array}{l}P_{0}>0 \\ T<0\end{array}\right.\right.\right.$,

and based on the existence condition of non-zero solution of the system of homogeneous equations (4.10), the following equation can be obtained:

$-4 \bar{k} l+\left(1+\bar{k}^{2}\right)\left(1-l^{2}\right) \operatorname{sh}(\bar{k} \ln l)+2 \bar{k}\left(1+l^{2}\right) \operatorname{ch}(\bar{k} \ln l)=0$.

Consequently, for the plate losing the plane stability, either $P_{0}$ or the minimal critical value $|T|$ can be determined.

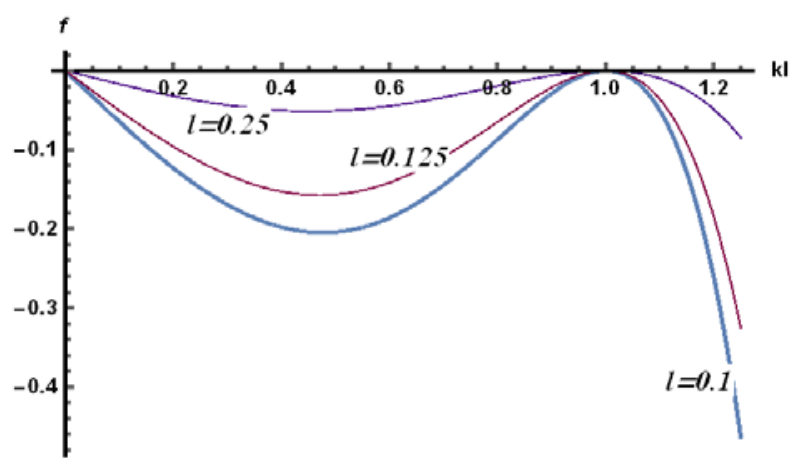

Figure 5. Characteristic stability curves of a circular ring plate with a joint thermo mechanical load from equation (4.11) and satisfying the boundary conditions (4.3)

Replacing $B_{i}$ with $C_{i}$ and $\bar{k}$ with $k$ in equations (4.10) and (4.11), $C_{i}$ constants and the critical values of parameters can be determined if the force is stated by equation (3.17).

The characteristic lines in accordance with equation (4.11), for different linear dimensions $l=b / a$ of a circular disc, are shown in Figure 5. 
Taking into account that

$\left\{\begin{array}{l}P_{0}-\alpha T l^{2}<0 \\ P_{0} v^{*}+\alpha T=0\end{array} \Rightarrow\left\{\begin{array}{l}P_{0}\left(1+v^{*} l^{2}\right)<0 \\ \alpha T=-P_{0} v^{*}\end{array} \Rightarrow\left\{\begin{array}{l}P_{0}<0 \\ \alpha T>0\end{array}\right.\right.\right.$, and based on the second limiting case of the plate, the deflection $\mathrm{w}(x)$ and $z=\mathrm{w}^{\prime}(x)$ obtained from the equations (3.25) - (3.26), as well as, satisfying the boundary condition (4.1), the following system of equations can be defined:

$$
\begin{aligned}
& A_{0} J_{0}(k l)+B_{0} Y_{0}(k l)+C_{0} \ln (k l)+D_{0}=0 \\
& A_{0} J_{1}(k l)+B_{0} Y_{1}(k l)-\frac{C_{0}}{k l}=0 \\
& A_{0} J_{1}(k)+B_{0} Y_{1}(k)=0 \\
& A_{0} J_{1}^{\prime}(k)+B_{0} Y_{1}^{\prime}(k)-C_{0} \frac{1-v}{k^{2}}=0,
\end{aligned}
$$

where $k^{2}=12(1-v)\left|P_{0}\right| a^{2} / h^{2}=12(1-v) \alpha T a^{2} / h^{2} v^{*}$

Based on the existence condition of non-zero solution of the system of homogeneous equations (4.12), the following transcendent equation can be obtained:

$$
J_{1}(k l) Y_{1}(k)-J_{1}(k) Y_{1}(k l)=\frac{2}{\pi l(1-v)} .
$$

Based on the known physical mechanical constants and geometrical parameters, the minimal positive value of $k$ can be gotten from the equation (4.14), and either the value of the force $\left|P_{0}\right|_{c r}$ or the value of temperature $T_{c r}$ corresponding to the value of $k$ can be obtained from equation (4.13).

The characteristic lines in accordance with equation (4.14), for different linear dimensions $l=b / a$ of a circular disc, are shown in Figure 6 .

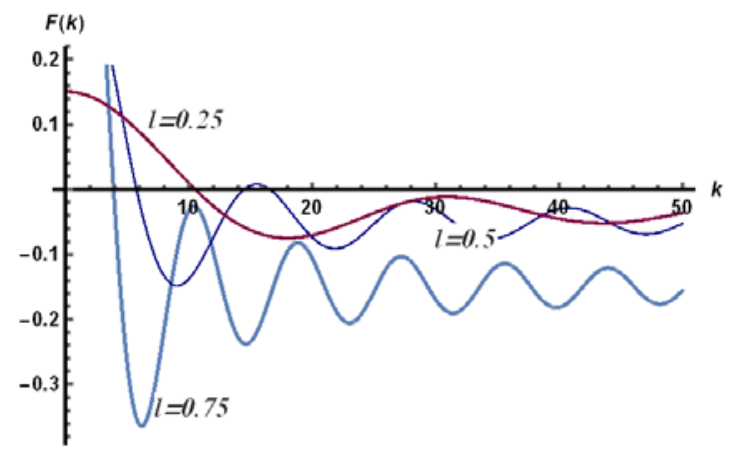

Figure 6. Characteristic stability curves of a circular ring plate with a joint thermo mechanical load from equation (4.14) and satisfying the boundary conditions (4.1) 
Therefore, if the inner radius of circular ring plate $b \rightarrow 0$, i.e. the circular ring plate is reduced to the circular plate, the components of displacement $u(r)$ and internal forces corresponding to $u(r)$ will act on the mid-plane of the plate.

Then, we will have the following values:

$u=C_{1} r, N_{r}=N_{\theta}=\frac{E h}{1-v}\left(C_{1}-\alpha T\right), N_{r \theta}=0,0 \leq r \leq a$

Satisfying the boundary condition $\left.N_{r}\right|_{r=a}=\underline{P}$, the following expressions are obtained:

$C_{1}=P(1-v) / E h+\alpha T, N_{r}=N_{\theta}=P \quad 0 \leq r \leq a$.

Therefore, the internal forces are not dependent on the changes of temperature (in the case of uniform thermal variations, stresses do not emerge in the body). The circular plate can lose its stability if $P<0$, so that the plate is subjected to the uniformly distributed compression $N_{r}=N_{\theta}=P<0$.

The problem of axisymmetric stability loss of the circular plate clamped on the border subjected to the uniformly distributed forces in the direction of the diameter edge is considered by Bryan [13]. The problem of plate clamped on the border is investigated by Dinnik [14].

\section{Conclusion.}

The values of the longitudinal displacement are determined based in the formed flat stress state in a circular ring plate for all cases of internal stresses in the compression zones.

In the case of a general load, the stress rings are expressed by both first-order and second-order Bessel functions, and by cylindrical functions of imaginary arguments with real indices. In the cases of partial loading of the ring plates, the stability equations of the plate take the look of Euler type equations, and the stresses in the plate are expressed by elementary functions.

The internal forces are not dependent on the changes of temperature (in the case of uniform thermal variations, stresses don't emerge in the body free of the external constrains). The circular plate can lose its stability if $P<0$, so that the plate is subjected to the uniformly distributed compression $N_{r}=N_{\theta}=P<0$.

\section{REFERENCES}

1. Dean W.R., The elastic stability of an annular plate, Proc. of the Royal Society of London, Ser. A, (1924), vol.106, pp.268-284.

2. Makushin V.M., Critical values of intensity of the radial compressive forces for circular thin plates, Strength calculation, (1959), N4, pp.271-298, (1960), N5, pp.236-248, (1960), N6, pp.171-181. [in Russian].

Макушин В.М., Критические значения интенсивности радиальных сжимающих сил для круглых тонких пластин// Расчеты на прочность.-М.:Машгиз, (1959), N4, стр. 271-298, (1960), N5, стр. 236-248, (1960), N6, стр. 171-181. 
3. Yamaki H., Buckling of a thin annual plate under uniform compression. Theory of Applied Mechanics, (1958), vol. 25, N 2, pp.266-273.

4. Khachatryan A.A., Stability of circular ring plate compressed by the radial forces applied by the external contour, Proc. of AS Arm. SSR, Mechanics, (1966), vol. 19, N6, pp.9-16. [in Russian],

Хачатрян А.А., Устойчивость круговой кольцевой пластинки, сжимаемой радиальными силами, приложенными по внешнему контуру. Изв. НАН Армении Механика, (1966), т. 19, №6, стр. 9-16,

5. Khachatryan A.A., Stability of circular ring plate subjected to tensile forces applied by the internal contour, Proc. of NAS RA, Mechanics, (1997), vol. 50, N2, pp.46-53, [in Russian],

Хачатрян А.А., Об устойчивости кольцевой пластинки под действием растягивающих сил, приложенных по внутреннему контуру, Изв. НАН Армении Механика, (1997), т. 50, №2, стр. 46-53,

6. Avetisyan A.S., Aleksanyan D.R., About a problem of circular ring plane stability subjected to the uniformly distributed normal load by the external and internal contours Proc. of NAS RA, Mechanics, (2006), vol. 59, N3, pp.13-20. [in Russian], Аветисян А.С., Алексанян Д.Р., Об одной задаче устойчивости круговой кольцевой пластинки под действием равномерно распределенной по внутреннему и внешнему контурам нормальной нагрузки, Изв. НАН Армении Механика, (2006), т. 59, №3, стр. 13-20,

7. Williams H.E., The stability of circular rings under a uniformly distributed radial load Technical report, Jan 15, 1970, 34p.

8. Vetyukov Y., Stability and Supercritical Deformation of a Circular Ring with Intrinsic Curvature, (2017), In book: Irschik H., Belyaev A., Krommer M., (eds) Dynamics and Control of Advanced Structures and Machines, Springer, Cham, https: //doi.org/10.1007/978-3-319-43080-5_3

9. Paimushin, V.N., Ivanov, V.A., Stability of a Circular Sandwich Ring under an Axially Symmetric Temperature Field Inhomogeneous across the Thickness, Mechanics of Composite Materials (2001) vol. 37, iss. 5-6, pp. 495-510, https://doi.org/10.1023/A:1014273415

10. V.N. Paimushin, V.A. Ivanov, S.N. Bobrov, and T.V. Polyakova, "Stability problem of a circular sandwich ring under uniform external pressure," (2000)Mech. Compos. Mater., 36, No.3, 185-192.

11. Timoshenko S.P., Guder J., Theory of elasticity, (1979), Trans. from English. Edited by. Shapiro G.S., M: Nauka, 560 p, [in Russian],

Тимошенко С.П., Гудер Ж. Теория упругости, (1979), пер. с английского. под Ред. Шапиро Г.С., М.: Наука, 560 с.

12. Timoshenko S.P., Stability of bars, plates and shells, (1971). Nauka, Moscow, [in Russian], Тимошенко С.П., Устойчивость стержней, пластин и оболочек, (1971). 
13. G.H. Bryan, On the stability of a plane plate under thrust in its own plan, with applications the 'buckling' of the sides of a ship, Proc. of the London Math. Soc., (1891), vol. 22, pp. 54-67.

14. A.Ch. Dinnik, About the stability of the compressed circular plate, Proc. of Kiev Polytech. Institute, Ukraine (1911), [in Russian]

Динник А.Х., Об устойчивости сжатой круглой пластины, Учеб. киевский политех. Институт, Украина (1911).

\section{Information about the authors:}

A.S. Avetisyan - Institute of Mechanics of NAS of Armenia, Doctor of Science, Prof., email: ara.serg.avetisyan@gmail.com

R.K. Aleksanyan - Yerevan State University of Architecture and Construction, Doctor of Science, Prof., e-mail: davidaleksanyan@gmail.com

D.R. Aleksanyan Yerevan State University of Architecture and Construction, e-mail: davidaleksanyan@gmail.com

Received 31.01.2019 